\title{
Features of process of epoxidation of natural rubber scrap in water - xylene
}

\author{
Serhii Zybailo ${ }^{1, *}$, Viktor Ved ${ }^{1}$, and Denis Shapovalov ${ }^{1}$ \\ ${ }^{1}$ Ukrainian State University of Chemical Technology, 49000, Dnipro, Haharina Ave., 8, Ukraine
}

\begin{abstract}
The article presents the analysis of the existing methods of producing epoxidized polydiene rubbers in order to obtain new derivative materials with improved physical and mechanical properties. The study proves the use of natural rubber as a raw material for the production of epoxidized polydiene. It has been experimentally demonstrated that conducting epoxidation as a combined-separation process allows producing epoxidized rubber in one reaction volume. It has been also found that the use of a water-xylene environment for the process has a qualitative effect on the degree of epoxidation and significantly reduces power consumption.
\end{abstract}

\section{Introduction}

Currently, the problem of rust prevention of production equipment remains still relevant, especially in the coal industry, which uses a significant amount of ferrous metals for the supports of mining work, pipelines, reinforcement of shafts, surface structures, as well as for the production of mining equipment. Operating conditions of metal structures in mines (the presence of dust, gas, acid and alkaline water, high alternating loads) promote intensive corrosion, which destroys valuable equipment, leads to machine downtime, loss of their productivity, and increases the cost of repair [1].

One of the methods to prevent corrosion of metals in the coal industry is the barrier method, which applies coatings based on inorganic or organic materials (polymers). The most promising protective coatings are epoxidized polymer films, which have high protective properties (oil resistance, resistance to corrosive media, gas-tightness), are easy to apply, and low-cost; they can be restored during operation and also easily disposed of. These characteristics make epoxidized polymers suitable to protect mining equipment from corrosion during its operation or temporary preservation, as well as to produce rubber elements of mining machines, which can significantly increase their efficiency and service life (sometimes 10-100 times or more) [2].

\section{Analysis of existing methods of epoxidation}

There is a common method of producing epoxidized 1,2-polybutadienes by treating a polymer solution in an organic solvent with an aqueous solution of sodium hypochlorite, which uses atactic or syndiotactic 1,2-polybutadiene with an average static molecular weight $\mathrm{Mn}$ from 1000 to 150,000 containing macromolecular links of $60-95$ mol. \% [3]. The disadvantage of

\footnotetext{
*Corresponding author: szybaylo@ukr.net
} 
this method is the complex procedure, which includes a mixing device, additional energy costs for mixing, high cost of raw materials, and the use of corrosive agent - sodium hypochlorite.

There is a known method of obtaining epoxidized 1,2-polybutadiene by reacting a polymer solution in an organic solvent with a mixture of hydrogen peroxide, sodium tungstate, and phosphoric acid in the presence of an interphase catalyst - cetylpyridine chloride [4]. The disadvantage of this method is the high cost of raw materials, including the use of 6 components; the use of an additional catalyst that must be periodically restored; the complexity of the method of synthesis and design of the apparatus equipped with a mixing device; additional energy costs for mixing; the need to maintain a preset $\mathrm{pH}$ level with the introduction of additional reagent; and a low degree of epoxidation.

The work [5] proposes a resource-saving technology that allows processing natural rubber scrap by its epoxidation in a water-xylene environment. The epoxidation reaction is a random process and, therefore, the attachment of oxygen to the double bonds distributed along the polymer molecule proceeds randomly. At very low levels of epoxidation, the reaction proceeds more simply, as the individual isoprene units are "freely" arranged along the main chain of the molecule. However, the reaction rate increases with increasing acid content, which creates more epoxied blocks (up to $15 \mathrm{~mol}$ \% or higher) along the skeleton of epoxy natural rubber (ENR). The obtained ENR with a content lower than 50 mol. \% of epoxy groups is a typical elastomer, stickier than NR due to the presence of epoxy groups, translucent or opaque, dirty white substance with a slight yellowish tint [6].

The need for modification of natural rubber is emphasized in the work [7]. One of the common areas of modification is epoxidation. Currently, many techniques have been created and studied for epoxidation of elastomers in various organic media or aqueous systems (latexes). These techniques are mostly for laboratory experiments and of little use in industry, as they are impractical, difficult and not flexible enough, requiring high energy costs or the use of catalysts (Table 1) [8].

Tab. 1. A summary table of the conditions and indicators epoxidation of polydienes.

\begin{tabular}{|c|c|c|c|c|c|c|}
\hline № & Raw materials & $\mathrm{MC}^{1}$ & $t,{ }^{\circ} \mathrm{C}$ & $\tau$, min. & $\mathrm{DE}^{3}, \%$ & $\mathrm{CEA}^{4}$ \\
\hline 1 & 1,2-polydiene [9] ${ }^{2}$ & $1: 1.33$ & 45 & 320 & 31.0 & 0.233 \\
\hline 2 & $\begin{array}{c}\text { 1,4-polyisopren } \\
\text { (a latex of NR) [8] }\end{array}$ & $1: 0.75$ & 60 & 300 & 42.4 & 0.650 \\
\hline 3 & $\begin{array}{c}\text { 1,4-polyisopren } \\
\text { (a scrap of NR) [10] }\end{array}$ & $1: 0.71$ & 93 & 180 & 36.6 & 0.515 \\
\hline
\end{tabular}

Notes: 1 - molar ratio of polymer/hydrogen peroxide; 2 - process in the presence of a catalyst and stirring; 3 - epoxidation degree; 4 - conversion of epoxidizing agent.

The molar ratio of polymer/hydrogen peroxide should be 1:0.4-0.8, because an increase in the concentration of $\mathrm{H}_{2} \mathrm{O}_{2}$ in the reaction mixture leads to uncontrolled oxidation of the rubber and the reaction of its decomposition without producing ENR. In this case (Table 1, item 1) to achieve high $\mathrm{CO}$ values it is necessary to carry out the process at low temperature $\left(45^{\circ} \mathrm{C}\right)$ for a longer time with the use of catalysts, which is unproductive since it reduces the conversion of epoxidizing agent.

A decrease in the degree of epoxidation by virtue of the increasing amount of hydrogen peroxide in the reaction (Table 1, item 2) can be due to two reasons: 1) non-selective decomposition of hydrogen peroxide; and 2) the occurrence of adverse reactions of the epoxy ring opening.

In addition, an estimate of the decomposition of hydrogen peroxide at $60^{\circ} \mathrm{C}$ showed that only $8 \%$ of hydrogen peroxide decomposes within 8 hours. Therefore, the decrease in the content of epoxy groups is associated with the occurrence of adverse reactions with their participation [8].

Thus, polydiene epoxidation is a complex resource- and energy-consuming chemical 
process, the efficiency of which depends more on the mixing of the reaction volume. Therefore, the objective of the research was to introduce energy and resource conservation in the epoxidation of polydienes.

\section{Methodology}

The time effect of the epoxidation of NR scrap on the degree of epoxidation (DE) and the conversion of epoxidizing agent $(\mathrm{CEA})$ at the optimum process temperature $\left(93^{\circ} \mathrm{C}\right)$ was determined in the work [11].

The reaction mixture in the laboratory reactor was heated to boiling point, which was measured with a digital thermometer with an accuracy of $0.1{ }^{\circ} \mathrm{C}$. The vapors were bubbled through a layer of solution, vigorously stirring it to form a foam phase on the surface. The solvent vapor was returned to the reaction mixture by cooling in reflux.

After complete consumption of epoxidizing agent (EA) - hydrogen peroxide, the resulting reaction mass was cooled to room temperature, washed with distilled water, and precipitated ENR with ethanol.

The degree of epoxidation, the conversion of the epoxy agent, the analysis of the composition of the obtained product was carried out according to the methods described in the work [11].

\section{Results and discussion}

Resource saving in the work was achieved by replacing the manufactured industrial polydiene with its waste - NR scrap with a molecular weight of up to $300 \mathrm{k}$.

Given that the heat consumed to heat the reaction mass depends on the time of the heating and the heat flow from the heater, to introduce energy savings, it is necessary to reduce the values of these indicators while maintaining the level of DE and CEA.

The thermal regime of the epoxidation process by bubbling the epoxy agent through the solution layer was studied and shown in Fig. 1.

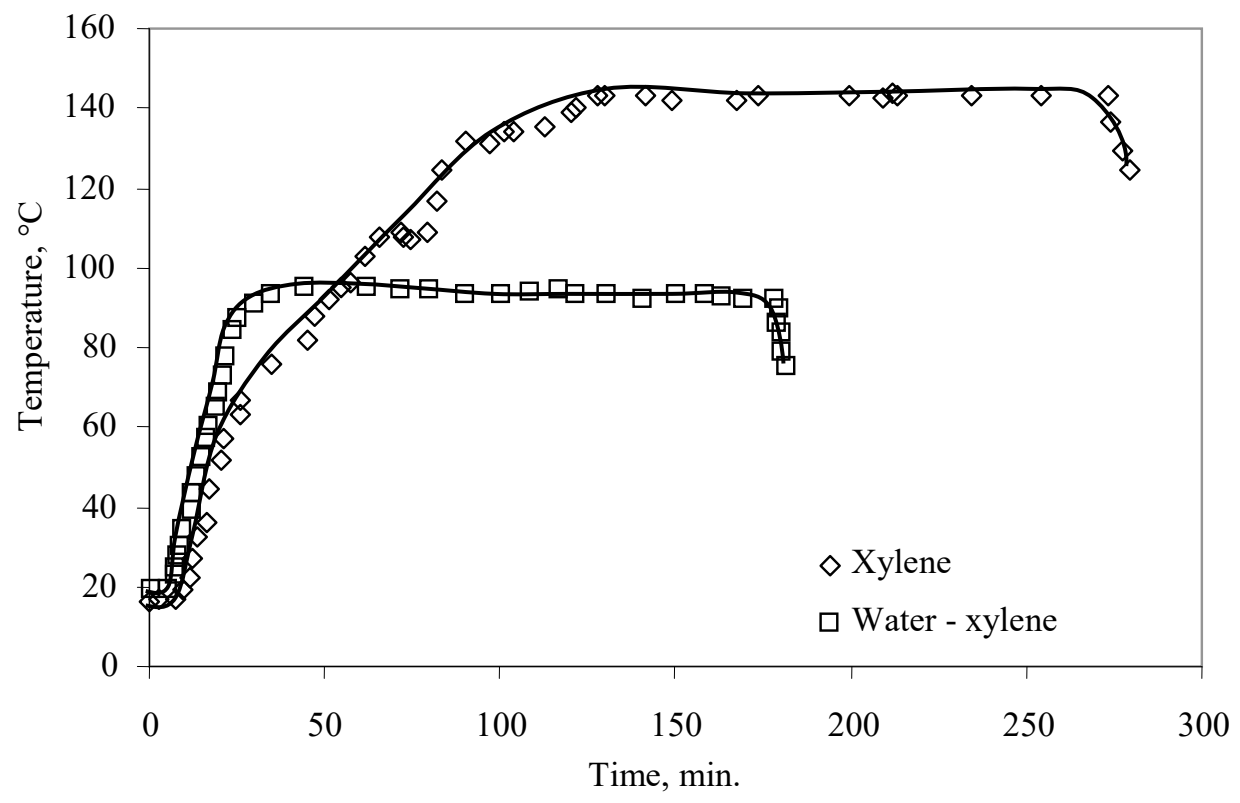

Fig. 1. Thermal regime of natural rubber epoxidation. 
The heating was started at a temperature of $18^{\circ} \mathrm{C}$. Upon reaching the boiling point of the mixture, a combined reaction-separation process begins, the description of which is given in the work [12]. An epoxidizing agent was administered for 2 hours, which led to a gradual increase in DE (Fig. 2).

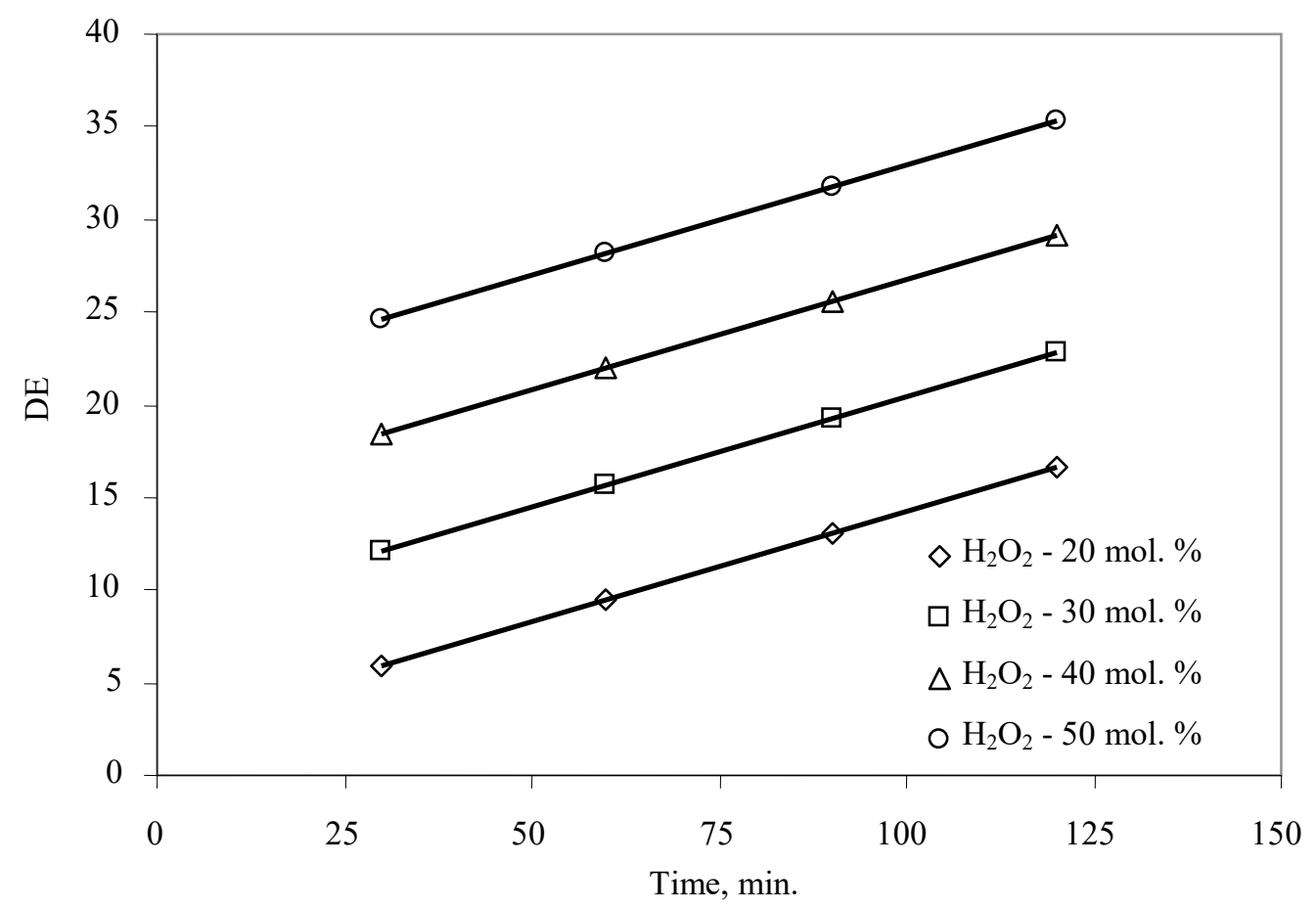

Fig. 2. Effect of time of natural rubber epoxidation at $93{ }^{\circ} \mathrm{C}$ on the degree of epoxidation.

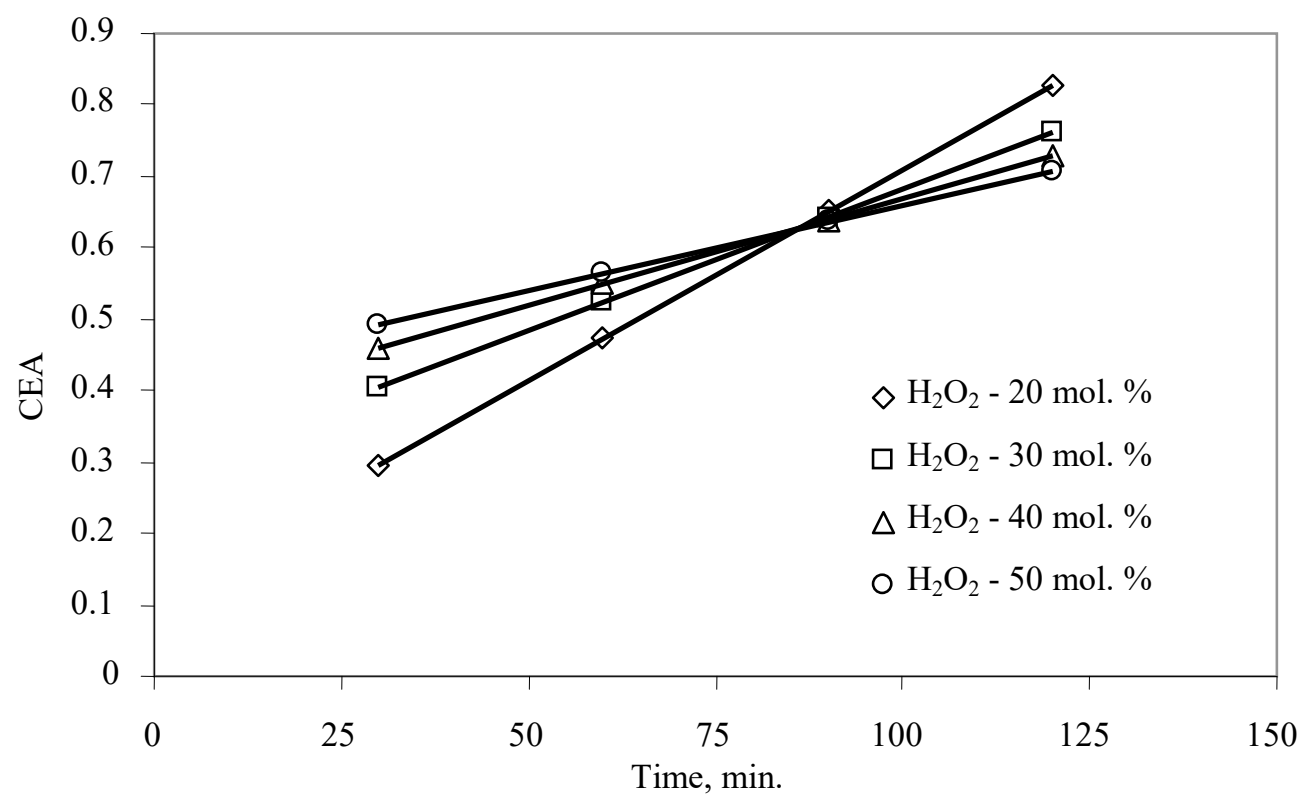

Fig. 3. Effect of time of natural rubber epoxidation at $93{ }^{\circ} \mathrm{C}$ on the conversion of epoxidizing agent. 
It is established that the use of a xylene-water mixture of solvents reduces the epoxidation time from 5 to 3 hours, as well as the heating temperature of the mixture - from $143{ }^{\circ} \mathrm{C}$ to $93{ }^{\circ} \mathrm{C}$. All this helps saving energy not only by reducing the total heating time, but also by reducing the required heat flow.

The kinetics of the epoxidation process with boiling water-xylene mixture was investigated in the work [13]. It was found that the conversion of epoxy agent during boiling at $93{ }^{\circ} \mathrm{C}$ is influenced by the amount of EA (Fig. 3): with increasing volume of EA, the conversion gradually decreases with time due to adverse reactions.

In accordance with the above relationships and results of the works [10-13], an epoxidized natural rubber of 25 mol. \% epoxidized groups (ENR-25) was scientifically substantiated and obtained using the energy- and resource-saving principles.

\section{Conclusions}

Reducing the concentration of epoxidizing agent does not allow to obtain the desired degree of epoxidation but leads to an increase in the conversion of epoxidizing agent due to the attachment to the terminal groups (oxidation of the terminal groups of NR).

The process at $91-93{ }^{\circ} \mathrm{C}$ allows increasing the reaction rate and achieving bubbling of boiling steam with epoxydixing agent through a layer of polydiene solution. This makes it possible to obtain an epoxidized product from rubber scrap due to bubbling aqueous solutions of epoxidizing agent through a solution of polydiene when heated, which reduces both its dosage to equimolar ratios and the time of the epoxidation process.

We managed to introduce energy-saving principle in the epoxidation of polydiene by changing the composition of the solvent and effectively stirring the reaction mixture, carrying out all the processes in one reaction volume.

Thus, the developed principles of introduction of energy- and resource-saving techniques in polydiene epoxidation allow considering their use in industry due to high quality production against the background of low energy costs, simplified reactor design, and improved process security.

\section{References}

1. Dyrda, V. Kobets, A. Bulat, I. Lapin, V. Lysytsia, N. Ahaltsov, H., Sokol, S. Vibroseismic protection of heavy mining machines, buildings and structures. E3S Web of Conferences, International Conference Essays of Mining Science and Practice, 109 (2019). https://doi.org/10.1051/e3sconf/201910900022

2. Bulat, A. Voloshyn, O., Zhevzhik, O. (2013). Plasma reactor for thermochemical preparation of coal-air mixture before its burning in the furnaces. Annual ScientificTechnical Colletion - Mining of Mineral Deposits 2013. 39-44. https://doi.org/10.1201/ b16354-8

3. Abdullin, M.I., Glazyrin, A.B., Kukovinets, A.S., Basyrov, A.A., Valekzhanin, I.V., Klisova, G.U. (2012) Sposob polucheniia epoksidirovannykh 1,2-polibutadienov. Patent № 2465285, Russia

4. Abdullin, M.I., Glazyrin, A.B., Kukovinets, A.S., Basyrov, A.A., Valekzhanin, I.V., Klisova, G.U. (2013) Sposob polucheniia epoksidirovannykh 1,2-polibutadienov. Patent № 2486207, Russia

5. Shapovalov, D.O., Ved, V.V., Zybailo, S.M., Yushko, V.L. (2014). Epoxidation of natural rubber in water-xylene environment. Voprosy khimii i khimicheskoi tekhnologii, (3), 102106. https://doi.org/10.6084/m9.figshare.12084069

6. Kwo, K.H. (2007). Study of adhesion properties of natural rubber, epoxidized natural rubber, and ethylene-propylene dieneterpolymer-based adhesives. Universiti Sains Malaysia (USM). Penang, Malaysia 
7. Fituni, Yu.A., Trachevskyi, V.V. (2011). Investigation of modifications of natural rubber with ethylene glycol. Vostochno-Evropeyskiy zhurnal peredovykh tekhnologiy [EasternEuropean Journal of Enterprise Technologies], 3 (6), 44-47

8. Akhmedianova, R.A., Miloslavskii, D.G., Kharlampidi, K.E., Dak, V.M., Tkhai, N.T., Liem, N.T. (2015). Epoxidation of styrene-butadiene and natural rubber in the form of latex with hydrogen peroxide in the presence of a peroxophosphate-tungstate catalyst system. Promyshlennoe proizvodstvo i ispolzovanie elastomerov, (4), 3-6

9. Osamu, H. Hideo, K. Yukio, M. (1985) Process for producing hydrophilic polymers. Patent № US4528340A, USA

10. Shapovalov, D.O., Zybailo, S.M., Yushko, V.L. (2017) Sposib otrymannia epoksydovanykh polidiieniv. Patent № 118007, Ukraine

11. Zybaylo, S. Ved, V. Okhtina, O. Kiselev, V. Shapovalov, D. (2019). Optimization of the process of obtaining epoxidized natural rubber for the development of new composite materials on its basis. Technology audit and production reserves, 6, 3(50), 10-15. https://doi.org/10.15587/2312-8372.2019.184364

12. Shapovalov, D.O. Zybailo, S.M. Yushko, V.L. (2014). Combined reaction and separation process for the epoxidation of natural rubber waste. Sovremennye innovatsionnye tekhnologii podgotovki inzhenernykh kadrov dlia gornoi promyshlennosti i transporta. 324327. https://doi.org/10.6084/m9.figshare.12084717

13. Shapovalov, D.O. Zybailo, S.M. Ved, V.V. (2016). Studies on the kinetics of epoxidation of natural rubber scrap. Sovremennye innovatsionnye tekhnologii podgotovki inzhenernykh kadrov dlia gornoi promyshlennosti $i$ transporta. 220-225. https://doi.org/10.6084/ m9.figshare.12084741 